\title{
Gender Gap in Housework: Couples’ Data Analysis in Kyrgyzstan
}

Kamila Kolpashnikova, University of Oxford, 42-43 Park End Street OX1 1JD, Oxford, United Kingdom, Tel: +44 (0)1865 281338, Email:

kamila.kolpashnikova@,sociology.ox.ac.uk

Man-Yee Kan, University of Oxford, 42-43 Park End Street OX1 1JD, Oxford, United Kingdom, Tel: +44 (0)1865 281338, Email: man-yee.kan@sociology.ox.ac.uk

\begin{abstract}
We analyze couples' time-use diaries from the 2012-2013 Life in Kyrgyzstan data. Using the pooled Blinder-Oaxaca decomposition method, we test the relative resources, time availability, absolute resources, and gender-centered frameworks in their ability to explain gender differences in housework participation among Kyrgyzstani women and men. The results show that among the three resource-based approaches, the time availability models are the most potent in accounting for the gender gap in housework, followed by the relative resources framework. Both frameworks emphasize household bargaining processes and power differentials between spouses. The findings suggest that among Kyrgyzstani couples, partners' time availability and, with it, bargaining power play an important role in the division of housework tasks. In contrast, absolute resources can account only for a small portion of the gender differences in housework participation.
\end{abstract}

Keywords: housework tasks, Kyrgyzstan, gender gap, time use 
Résumé : Nous analysons les emplois du temps de couples issus des données « La vie au Kirghizistan » («Life in Kyrgyzstan ») de 2012-2013. En utilisant la méthode de décomposition groupée de Blinder Oaxaca, nous testons les ressources relatives, la disponibilité temporelle, les ressources absolues et une approche basée sur le genre dans leur capacité à expliquer les différences liées au genre sur la participation aux tâches ménagères entre les femmes et hommes Kirghizes. Les résultats montrent que parmi les approches basées sur les ressources, les modèles sur la disponibilité temporelle sont les plus aptes à prendre en compte les écarts liés au genre dans les tâches ménagères, suivis par l'approche des ressources relatives. Ces deux approches soulignent les processus de négociation et le différentiel de pouvoir entre les conjoints. Les résultats suggèrent que parmi les couples Kirghizes, la disponibilité temporelle des partenaires, ainsi que le pouvoir de négociation ont une importance dans toutes les tâches ménagères, alors que les ressources absolues ne peuvent seulement expliquer qu'une petite part des différences de genres dans la participation aux tâches ménagères.

Mots-clés : tâches ménagères, Kirghizistan, différence de genres, emploi du temps 
Housework research remains important because most dimensions of gender inequality are not publicly regulated and are located outside of the labor market, in households. The quantitative part of the research focused mainly on the variations within two modal gender groups and the aggregate measures of housework, whereas to this day only a handful of studies provided a comprehensive analysis of the factors driving the persisting gender gap in the different categories of housework tasks (e.g., see Pepin et al. (2018) and Álvarez and Miles (2003)). It is important to analyze the gender gap itself because the factors that explain housework participation within groups such as only among women or only among men are distinct from those, driving the differences between gender groups. The gender gap analysis, therefore, is essential to understanding gender inequality, the policy interventions in the labor market, and social and individual factors affecting the relative time poverty and time demands among women and men (Walker, 2013).

Moreover, housework studies often remain domestic in another sense. They rarely venture outside of the Western world: Canada (Guppy and Luongo, 2015; Guppy et al., 2019; Schieman et al., 2018), United States (Pepin et al., 2018), European Union (Gimenez-Nadal and Sevilla, 2012; Kan et al., 2011), and Australia (Baxter, 2002; Craig et al., 2016; Tai and Baxter, 2018). Only a few studies focused on other regions such as East Asia (Kan and He, 2018; Kan et al., 2019), Latin America (Amarante and Rossel, 2017), or Central Asia (Osmonaliev et al., 2016; Walker, 2013). Analyzing housework in heterogeneous cultural contexts is necessary to test the applicability of theoretical frameworks in a variety of cultural and economic contexts. Post-Soviet regime countries offer a unique value because of 
the recent reversal to more traditional gender relations, opposite to what has occurred in the global north (Canada and the US). Such haphazard trajectories of sociopolitical history challenge the linear perceptions of the evolution of gender relations.

Additionally, it is vital to analyze samples of married couples to tackle the gender gap and the issue of imbalanced division of labor in heterosexual households (Zhou and Kan, 2019). Yet, the couple's data are usually unavailable with more widely known time use surveys such as the American Time Use or the Canadian General Social Surveys. The Life in Kyrgyzstan dataset provides a unique opportunity to analyze the division of labor between women and men in heterosexual couples, performing the Blinder-Oaxaca decomposition (Blinder, 1973; Oaxaca, 1973) of the gender gap in housework tasks and choose Kyrgyzstan as the analytic setting. The purpose of this project is to examine factors responsible for gender differences in time allocation to domestic tasks between married women and men. The study will address two main research questions: (1) which factors drive a more equitable division of labor in housework tasks and (2) whether the gender gap in time spent on different housework tasks can be accounted for by the same theoretical framework(s).

\section{THEORETICAL APPROACHES}


There are two main directions in the theoretical development of housework research: the resource-based and gender-centered approaches. There are three main resource-based theories. The relative resources framework argues that a partner with more resources must also have more power, which allows eschewing housework while exchanging economic resources with one's partner for housework. This perspective highlights power relations and domination in partnerships, as well as gender conflict inherent to heterosexual partnerships. For instance, Blood and Wolfe (1960) presented evidence that a man's relative power in households increased proportionately to his level of individual resources such as waged earnings, the level of education, and occupational status. The second perspective within the resource-based framework posits that time can also be one of the bargaining resources. The time availability approach relies on time differentials between spouses to explain the differences in housework participation (Blood and Wolfe, 1960; Hook, 2004).

The third approach is referred to as the absolute resources perspective. Gupta (2007) brought to the attention that the division of domestic labor could be driven by processes other than bargaining. Gupta (2007) argued that individual resources (absolute resources) allow husbands and wives to outsource their own shares of housework to hired help, thus decreasing the amount of housework. More recent studies in the housework research, for instance, Killewald and Gough (2010), confirm that the absolute resources approach is more capable in the explanation of the levels of housework participation in the global north. 
In the context of a country with high unemployment levels and low average income like Kyrgyzstan, it is hard to imagine that economic mechanisms, specifically those based on outsourcing, would be enough to explain the extant division of household labor. Among the three approaches of the resource-based framework, the power differentials are more likely to influence housework arrangements among Kyrgyz couples. Because the bargaining processes rely more on the relations of power than monetary resources and reflect a partner's subordination or domination relative to their spouse (Blood and Wolfe, 1960; Heer, 1963), we expect the following results in Kyrgyzstan:

Hypothesis 1: Bargaining with resources and time is expected to account for a larger share of the gender gap than absolute resources in all housework tasks in Kyrgyzstan.

Unlike relative resources and relative spousal power, absolute resources and outsourcing are more likely to work in less traditional contexts. In fact, Killewald and Gough (2010) and Pepin et al. (2018) also point out that the economic explanations might have increased their prominence concurrent with the increased gender egalitarianism in the global north. In traditional societies, however, more gendered mechanisms are still expected to buttress the gender differences in paid and unpaid labor. 
When the housework participation patterns contradicted the expectations of the resourcebased perspectives, scholars appealed to the gender-centered approaches (Brines, 1994; Greenstein, 2000; Kolpashnikova, 2018; Treas and Tai, 2016). These approaches evolved in housework research together with the advances in gender research. In the early 1980s and 1990s, they focused on sex roles (Blair and Lichter, 1991; Presser, 1994), later—on gender display (Baxter and Hewitt, 2013; Bianchi et al., 2006), and then-on gender ideology (Davis and Greenstein, 2013; Zhou, 2017) and 'doing' gender (Artis and Pavalko, 2003; Baxter and Hewitt, 2013; Bianchi et al., 2006; Brines, 1994; Deutsch, 2007; Evertsson and Nermo, 2004; Greenstein, 2000; Hook, 2010; Kan, 2008; West and Zimmerman, 1987).

According to the gender-centered perspective, societal expectations around gender and its performances define the gendered character of the housework division. Studies of this approach provide cultural framing to explain the diverging housework participation between women and men. For instance, although some research offers counter-evidence (Dernberger and Pepin, 2020), the majority of scholarship posits that the gender gap narrowed due to the diffusion of gender egalitarianism among younger generations (Gershuny, 2000) and a cultural shift in gendered expectations (Davis and Greenstein, 2013). Similar processes have not been as fast in countries outside the Western world (Kan et al., 2019). In some cases, the societies even experience the return to more traditional gender expectations and, with them, more traditional gender performances. One such society is Kyrgyzstan. 
According to the gender-centered perspective, gender relations within a household are embedded within society and, as such, represent a cultural 'site for doing gender' and an economically-driven 'gender factory' (Berk, 1985). The gender relations in Kyrgyzstan, therefore, reflect a traditional stage for gender performances, which reproduces traditional genders. In such societies, we could expect that gender ideologies among partners play a leading role in explaining the division of housework than resource-based factors.

In other words, in more traditional countries like Kyrgyzstan, women and men are likelier to 'do' and perform their traditional genders. Moreover, waged employment is not stable both for women and men compared to the countries of the global north. Therefore, we would expect that the gender-centered perspective should be able to account for the gendered division of labor in Kyrgyzstan better than the resource-based frameworks:

Hypothesis 2: The gender-centered framework factors are expected to account for a larger share of the gender gap than the resource-based framework factors in all housework tasks.

Table 1 summarizes the main theoretical frameworks and the associated variables. Conventionally, the relative resources framework is tested by the income transfer variable (Brines, 1994; Greenstein, 2000), the time availability approach—by the time spent on paid work and other activities, as well as the employment status (Artis and Pavalko, 2003), the 
absolute resources approach—by personal income (Gupta, 2007; Killewald and Gough, 2010), and gender ideology — by gender attitudes (Davis and Greenstein, 2009). Additionally, we included intra-household decision-making variables to test the gender-centered perspective.

[Table 1 about here]

\section{Types of Housework}

Housework is heavily gendered, and substantial task segregation by gender still exists (Shelton, 1992). Task segregation implies that domestic tasks vary in the degree of their association with a traditional gender depending on cultural expectations (Coltrane, 2000), which are more onerous in traditional societies. Whereas some tasks, like maintenance and repairs, are associated with men and considered 'masculine,' the majority of housework tasks are commonly associated with women's work and considered 'feminine' (Coltrane, 2000).

Overall, men tend to do more casual and non-routine tasks, whereas more routine and timeconsuming housework usually burdens women (Guppy and Luongo, 2015; Kan et al., 2011). Using data from the Multinational Time Use Survey, Kan et al. (2011) show that women still 
do most of the routine housework even though men increased their involvement in nonroutine domestic work. Similarly, Guppy and Luongo (2015) show that in Canada, domestic work remains gender-segregated, and women do most of the routine housework and mennon-routine.

Moreover, some tasks do not have a clear association with any gender group and are sometimes referred to as 'gender-neutral' or 'traditionally shared' tasks. Coltrane (1990) mentioned bill paying and driving as shared tasks. However, it is shopping that takes the most time, especially when travel time is included within the category (Baxter, 2002; Craig et al., 2016). On the theoretical level, the gender attribution of housework performance transcends the binary categorization of typically 'feminine' and 'masculine.' Still, empirically in the quantitative research of housework, the categorization tends to lean toward the analysis of only two modal gender groups (Goldberg, 2013).

Based on housework types, we can expect to find differences in how much the main theoretical frameworks can account for the gender gap in different tasks. Recent scholarship emphasizes the need to analyze housework tasks separately (Hook, 2006, 2010). The taskspecific analysis is especially relevant in the view of the persistent gender-essentialist stereotypes, which are partially responsible for the tenacity of gender inequality in more traditional societies such as Kyrgyzstan. 
Economic mechanisms (relative and absolute resources, time availability) are assumed to work regardless of gendered expectations (Baxter and Hewitt, 2013; Brines, 1994;

Greenstein, 2000; Gupta, 2007). In contrast, the gender-centered perspectives state that the association of a housework type with a particular gender might curb the ability of resource differentials to account for the gender gap (Killewald and Gough, 2010). Thus, in general, we could expect that the resource-based explanations would account for more in less gendered types, and the gender-centered approaches - in more gendered housework types:

Hypothesis 3: The gender gap is more likely to be explained by resource differentials in less gendered tasks such as shopping compared to more gendered tasks, whereas the gendercentered approach is more likely to account for more gendered tasks such as cooking and cleaning.

\section{METHODS}

We use couples' data from the 2012-2013 Life in Kyrgyzstan (LiK) dataset (Brueck, 2015). The LiK survey collected representative data in seven oblasts (administrative divisions) and two cities of Kyrgyzstan, using a stratified two-stage sampling technique. Sixteen strata included the two samples from the largest cities, Bishkek and Osh, and fourteen samples 
from the urban and rural areas of seven Kyrgyz districts. Each stratum was proportional to its population and contained a random sample of 25 households each. Reserve samples were used to balance for non-response. Twenty-seven percent of the original households in the data come from the reserve sample frame.

The LiK surveyed all individuals in the selected households and tracked them over time. This unique feature makes LiK suitable for the longitudinal analysis of couples. Unlike the American Time Use Survey or Canadian General Social Survey (Time Use), LiK contains longitudinal time-use diaries about partnered relationships. Moreover, it covers a range of socioeconomic topics, which are not usually present in large-scale time use surveys, including data on gender attitudes and intra-household decision making. In 2010, LiK interviewed more than 8000 people of 3000 households. Out of the 8160 individuals in the first wave, 6558 were re-interviewed in 2013. The attrition rate of households, estimated by the LiK team, was at the $18.6 \%$ level.

A few steps helped to arrive at the final analytical sample for the present project. Our primary sample is restricted to married couples, where both partners have responded to surveys in 2012 and 2013 and were present in the household. None of the respondents were migrants. We capped the age variable at the age of retirement, which was 60 years in Kyrgyzstan at the time. The gender attitudes variables, which are important for testing the gender-centered framework and gender performances, were only introduced in 2012 . Thus, 
the sample included the last two years (2012-2013) and not the two first years of the survey. The final analytical sample consists of 2,718 couples (see Table 2). Seventy-two percent reported being Kyrgyz, 13\%-Uzbek, and 5\% of the total sample report being ethnically Russian.

[Table 2 about here]

\section{Measures}

The dependent variables are the gender time gaps spent on all three housework tasks combined and individually: cooking, cleaning, and shopping. The cooking category included meal preparation and dishwashing. Cleaning consisted of house cleaning and laundry. The shopping category covered all types of shopping. The diaries in LiK were collected for every 30-minutes intervals starting at $4 \mathrm{am}$. We calculated the continuous time-use variables for each housework task by adding the number of time slots in the diary day reported for the housework activity and multiplied them by the number of minutes in each slot (30 minutes per slot).

In Table 2, we summarized descriptive statistics grouped by gender for the time spent on main housework tasks, for independent and control variables, and a few household composition variables, which were not included in the models. We did not include these 
variables because there were no differences in household composition between couples residing in the same household. We report significant differences between women and men's mean estimates for all housework tasks. For instance, on an average day, women spent 135 minutes on cooking, whereas men spent only 3. For comparison, American women spend 59 minutes daily and men—almost 20 minutes on cooking, and Canadian women and men -72 and 27 minutes, respectively (Kolpashnikova, 2016, 2018). The gender gap in routine housework participation in Kyrgyzstan is more substantial than in Canada or the US. The gap is a little more than two hours in cooking for Kyrgyzstan, whereas among North American women and men, it is less than an hour. Among three tasks, the narrowest gap is in cleaning, 50.5 minutes, making it effectively the most egalitarian task among Kyrgyz women and men, if time is compared in absolute values. This is different for Canada and the US, where shopping is a more egalitarian task than cleaning (Kolpashnikova, 2016, 2018). Among the three tasks, Kyrgyz men spend more time on cleaning, albeit still considerably less than women.

In the models, different sets of variables test each of the resource-based frameworks. These variables were adapted from the previous literature in housework research (see Table 1). For instance, we use the gap in income transfer to test the explanatory power of the relative resources argument (Brines, 1994; Sorensen and McLanahan, 1987). The income transfer variable is calculated as the difference of own income and partner's income, divided by total income. Income transfer ranges between -1 and 1 , where lower values indicate the higher levels of economic dependency on one's partner. The average income transfer for women is 
the mirror opposite of the mean estimate for men, -0.416 and 0.416 , respectively (see Table 2) because the sample includes only couples.

Table 1 shows that three variables can test the time availability approach in our models: the gender gap in time spent on paid work, the gender gap in employment status, and the gender gap in leisure time. Similar to men in the global north, Kyrgyz men spend more time on paid work than women. Descriptive findings of Table 2 show that whereas women spent 113 minutes on an average day in paid work activities, men spent about 257 minutes, which constitutes a statistically significant difference of more than two hours. There are also considerable differences among women and men in the rates of regular employment. Thus, only $47.9 \%$ of Kyrgyz women report being employed, whereas $77.4 \%$ of men report the same. Moreover, since recent studies show that women's employment alone does not guarantee an equal division of housework at home (Moreno-Colom, 2016), we also included leisure time as another independent variable testing the time availability framework. Time spent on leisure activities mainly covers screen time such as TV watching and internet surfing.

In our models, we test the absolute resources perspective using the measure of the gender gap in monthly waged income (Gupta, 2007). Men earned three times more than women (see Table 2), making about 140 dollars a month, on average (when the local currency is converted to US dollars, using the 2013 exchange rate). Kyrgyzstan struggles 
economically — the unemployment rate is high, employment is not stable, and gender differences in the pay gap are still substantial.

One advantage of using LiK over other time diary datasets is that it also allows measuring individual gender attitudes because the gender gap in gender attitudes is important for testing the gender-centered framework. These attitudes were measured using the following seven items in LiK: (1) "important decisions should be made by the husband rather than the wife"; (2) "a man's job is to earn money, a woman's job is to look after the home and family"; (3) "a woman is really fulfilled only when she becomes a mother"; (4) "a working woman can establish just as warm and secure of a relationship with her children as a mother who does not work"; (5) "a husband's career should be more important to the wife than her own"; (6) "a university education is more important for a boy than for a girl"; and (7) "both the husband and the wife should contribute to the household income." The response options were coded on the Likert scale, ranging from (1) "strongly disagree" to (4) "strongly agree." The reliability analysis showed $\alpha=0.65$ in 2012 and 0.67 in 2013 .

Variables relating to household composition variables, including those relating to the number of children, were not included in the decomposition models because they were identical in couples, with few exceptions. We can report, however, that the analytical sample included couples in a household with an average of about six household members, four of them being adults. The household sizes in Kyrgyzstan are, on average, much larger than in Western 
countries, where a nuclear family is more common than co-residence with the extended family. Almost thirteen percent report that their household has a labor migrant. Sixty-six percent of couples report living in a household with a child under 5 .

Furthermore, we added 25 different questions relating to the decision-making about household matters, such as the marriage of sons and daughters, purchases, and money issues. The decision-making also relates to the gender performances in housework participation and social expectations on such performances within households. The more decisions are made by a spouse, the more 'masculine' the role of the spouse is in a household. The answers recorded whether the decisions were done by themselves, by their spouses, or mutually. The measures sum the numbers reported in each category for 25 questions. There are discrepancies in the responses between women and men within couples about who makes the decisions. Therefore, Table 2 reports differences in the responses between gender groups. Women are more likely to respond that some decisions are made together, whereas men are more likely to respond that they made decisions by themselves. In fact, these differences in decision making also reflect the gender group differences in the levels of gender egalitarianism. Women are more likely to report more gender-egalitarian attitudes and behaviors in decision-making, whereas men are more likely to express responses revealing more traditional attitudes toward household decision-making. 
In previous literature, it was not possible to disentangle the effects of personality differences. Previous research suggests that couple's similarity in assortative mating is better measured by personality traits in rural Kyrgyzstan, where age and educational differences are not discernable by gender (Steiner and Becker, 2019). Steiner and Becker (2019) demonstrate that higher dissimilarities in the couple's personality profiles may indicate a higher probability of bride kidnapping, making personality trait variables of particular interest in the analysis of Kyrgyz data. Overall, LiK allows us to control for personality traits, making the unobserved (unexplained) gap less dependent on personality traits and more likely to indicate the presence of societal gender bias. The 'Big Five 21 questions tool' helps construct five personality dimensions: Extraversion, Agreeableness, Conscientiousness, Neuroticism, and Openness. Among the five dimensions, only the results for the Openness scale showed an acceptable level of internal reliability for the sample (Cronbach alpha $>0.6$ ), whereas others did not.

As controls, we included a number of demographic variables, such as gender gap in education and age, both measured in years, the dummy variables for the gender gap in the proportions of belonging to main ethnic groups: Kyrgyz, Uzbek, Russian, and other ethnicities. We used the gender gap in reporting being Kyrgyz as the reference category. We also control for the gender gap on whether the diary day was completed on a weekday or a Saturday/Sunday ( $1=$ 'weekday,' $0=$ 'Saturday or Sunday') because individual time-use diaries tend to vary significantly by the day of the week (Kolpashnikova and Kan, 2020). The time schedules of women and men may differ, and thus create differences in the reported 
diaries. Usually, women are more likely to be interviewed on weekdays because they are more likely to be out of the labor force than men.

\section{Models}

We employ the Blinder-Oaxaca decomposition method, which decomposes the effects into the 'explained' and 'unexplained' parts (Blinder, 1973; Oaxaca, 1973). For the underlying panel regressions, we use random-effects models, following the suggestions of Heitmueller (2005). Decomposition methods are more apt for cross-sectional data or random-effects models. The use of fixed effects in decomposition models is not advised because it confounds the results and becomes uninterpretable (Heitmueller, 2005). Thus, by using random-effects models, we attempted to reduce the issues related to time-invariant variables, such as education, attitudes, or personality traits. We ran the Breusch-Pagan Lagrange multiplier test, which helped justify the use of pooled regression with random-effects over repeated cross-sections $\left(\bar{\chi}^{2}=337.06, \mathrm{p}<.001\right.$ for the aggregate housework).

We also ran a few robustness checks for our models, such as using GMM estimation instead of OLS, the introduction of instrumental variables and implementations of the two-stage least squares models, and using simultaneous regression models, where we also tested the reverse direction of association of the time spent on housework tasks on paid work variable. The 
results for these checks were, overall, similar to those presented in this paper. Thus, we decided to use the simplest model with a more accessible interpretation, which still allowed making use of the panel structure of the data. We also clustered the standard errors in our models based on geographical strata to compensate for the sampling design.

\section{RESULTS}

Table 3 reports the summaries of the decomposition results for aggregate housework and separately for different housework tasks: 'feminine' routine tasks (cooking and cleaning) and 'shared' non-routine tasks (shopping). It shows the share of the gender gap, which can be explained by individual factors relating to each of the tested theoretical approaches: relative resources, time availability, absolute resources, and gender ideology.

[Table 3 about here]

Each cell of the 'Full Model' column in Table 3 represents the share of the gender gap explained or left unexplained by all factors in the decomposition models (see Table A1 in the Appendix for the detailed outputs). The 'explained' percentages report the share to which the time gap between women and men would decrease (positive percentages) if women had the same level as men in all model factors. For instance, if women had the same overall levels as 
men in personal income, education, age, paid work, gender attitudes, and other factors in the models, then the gender gap in total housework time would decrease by $26.4 \%$.

The 'Relative Resources,' 'Time Availability,' ‘Absolute Resources,' and 'Gender Ideology' columns in Table 3 summarize results for model specifications, testing one of the four frameworks. Thus, the relative resources approach is tested by the model that includes income transfer variable, the time availability approach-by the time spent on paid work, employment status, and leisure time, the autonomy perspective-by monthly personal income. Additionally, we test the gender-centered approach using a gender attitudes scale and intrahousehold decision-making variables.

First, we find support for Hypothesis 1 in Kyrgyz data. The gender gap in factors testing the bargaining perspective (relative resources and time availability measures) can account for more of the gender gap in all housework tasks compared to the absolute resources framework (see Table 3). This is true both when variables are analyzed separately or in full models, controlling for other variables. Moreover, gender differences in time spent on leisure, which also tests the time availability and the underlying bargaining processes between men and women, can account for about 5\% (11.998/237.903) of the gender gap in aggregate housework (see Table 4). This finding implies that the power differentials are more critical in the division of housework in traditional societies such as Kyrgyzstan, rather than the absolute resources, which might be more relevant in the global north (Killewald and Gough, 2010). 
Contrary to the results in the global north, the models based on absolute resources do not hold more explanatory power for the gender gap in housework among Kyrgyzstani women and men than the models based on the two bargaining perspectives. The results suggest that the decision-making in Kyrgyzstani households regarding the division of housework may rarely rely on the autonomous decisions by a partner but rather depends on bargaining processes, the differences in partners' relative resources, and their time availability.

Second, overall, our results do not support Hypothesis 2. Gender differences in gender attitudes and decision-making cannot explain any considerable share of the gender gap in housework tasks. In our decomposition models, these models can account for less than $5 \%$ of the overall gender gap in housework. This result is not, however, an assertion of the preeminence of the resource-based frameworks over gender-centered because the results only pertain to the differences between women and men in their gender attitudes. However, if models for women and men are estimated separately, gender attitudes have a substantial effect on the participation of women in housework and less so for men (outputs can be provided upon request).

Moreover, it is essential to note that a considerable share of the gender gap still cannot be accounted for by our models, leaving a large portion of the difference unexplained and, 
perhaps, primarily driven by gender discrimination or other unobserved variables. If these variables measuring gender discrimination are identified and accurately measured, it might be that gender-centered explanation will be able to account for more of the gender differences in participation in housework. Gender attitudes measure more internalized states, whereas more structural constraints, including discrimination, might be a more appropriate measure to test the gender-centered perspective.

Other variables that also test the gender-centered framework are the intra-household decision-making variables. Among them, it is the gender differences in the decisions by spouse variable that can explain at least $0.5 \%(1.094 / 237.903)$ of the gender gap in aggregate housework. The differences in decision-making between spouses are more applicable to the explanation of the gender gap in cleaning and shopping than in cooking tasks (see Models 4 in Tables 5-7). Thus, we can also report some marginal support for Hypothesis 2, using the intra-household decision-making variables.

Third, we do not find enough evidence to support Hypothesis 3. The resource-based framework models can explain a similar share of the gender gap in less gendered housework tasks such as shopping activities as in other more gendered tasks like cooking. In all three main types of housework in the analysis, we find that the resource-based frameworks explain similar shares of the gender gap: about a fourth of the gender gap in routine housework tasks or $26.4 \%$ in the overall housework time. This result may be because shopping tasks still have 
a strong association with 'women's work' in Kyrgyzstan compared to Canada or the US. Considering that in the Kyrgyz data, the gender gap is the narrowest and that the largest share can be explained in cleaning tasks (see Table 3), it can also be because of the different gendered meanings assigned to housework tasks in Kyrgyzstan compared to countries of the global north. Thus, this result suggests that there are cultural differences in the gendered meaning of cleaning, as well as shopping for Kyrgyzstani women and men compared to the Western world.

[Table 4 about here]

Additionally, interestingly we find some marginal significance of the explanatory power of the gender differences in personality traits such as agreeableness and extraversion, mainly in cooking and shopping. Agreeableness is the trait that indicates pro-social behavior. Our results show that the gender group differences in agreeableness scale (women score higher than men; see Table 2) account for a part of the gender gap in cooking. The results also show that extraversion (men score higher than women, on average; see Table 2) also accounts significantly for a part of the gender gap in shopping.

\section{Testing Frameworks by Housework Tasks}

Tables 5-7 summarize the results for all theoretical frameworks in cooking, cleaning, and shopping. The percent values associated with explained and unexplained parts can be 
interpreted as the values by how much the gender gap would increase (-\%) or decrease $(+\%)$ if women had the same level as men on the chosen model factors. For instance, in Table 5, $15.6 \%$ for the relative resources framework in cooking tasks indicates that if the gender gap in all factors of the models, which use the income transfer variable as the main factor, would close, the gender gap in time spent on cooking would decrease by $15.6 \%$ of its current value.

[Table 5 about here]

The models testing time availability hold the most explanatory power for the gender gap in all types of housework. The relative resources framework tested by the gender gap in income transfer, which also tests the bargaining perspective like the time availability framework, is the second most potent explanatory model of the gender gap among Kyrgyz couples (see Tables 5-7). It can account for $15.6 \%$ of the gender gap in cooking and $16.4 \%$ in shopping (see Table 7). It is also the highest predictor in cleaning tasks, where it can account for $17.7 \%$ of the gender gap.

The autonomy framework models can only account for a comparatively small portion of the gender gap in routine housework, even when models do not control for gender differences in other resource-based variables. They can explain $7.6 \%$ of the gender gap in cooking (Table 5) and $9 \%$ of the gender gap in shopping (Table 7). Spousal power and time availability 
differentials are more important in accounting for the gender gap in housework in Kyrgyzstan than the gender differences in absolute resources.

Besides bargaining processes, another reason why personal income does not appear to be as relevant in Kyrgyzstan as in other countries might be because of the nature of the labor market in the country. Many work without monetary pay, especially in rural areas and on farms. This is a clear limitation for the use of personal income as a measure of gender inequality in countries facing labor market difficulties and the high unemployment rates such as Kyrgyzstan.

[Table 6 about here]

[Table 7 about here]

The decomposition analysis showed that the gender differences in conventional variables that test the gender-centered framework provided only a small share of the explanation for the gender gap in routine housework, whereas the gendered expectations around decisionmaking still indicate that structural and cultural barriers to gender inequality persist. These findings suggest that there are limitations in measuring gender-centered framework using factors pertaining to individual agency, such as by gender attitudes, rather than from the 
structural constraints, including gendering and the systems of sexism. There is at least $69.5 \%$ of the gender gap in housework tasks that still cannot be accounted for by the factors discussed in the present paper (see Table 3). Likely, structural processes creating a system of oppression for women in housework occur regardless of the level of their education, resources, and gender attitudes and affect the gender gap among Kyrgyzstani couples more than individual resources, attitudes, and preferences.

\section{CONCLUSION}

The approaches employing economic resources can account for a sizeable portion of the gender gap in housework time. Compared to the gender differences in absolute resources and gender attitude factors, bargaining processes tested by the gender differentials in relative resources and time availability frameworks can account for the biggest share of the gender gap in the time spent on cooking, cleaning, and shopping among Kyrgyzstani women and men. Among the two, the time availability framework models can account for more of the gender gap, especially in cooking and shopping tasks. The results imply that the power imbalances between women and men still impede the processes pushing toward a more egalitarian division of housework.

Thus, leveling income differences and opportunities in the labor market, allowing women to engage in economic activities and earn as much as men would reduce the gender gap in all 
routine housework tasks, albeit only marginally. Although we find that gender differences in gender attitudes, using common measurement scales, do not account for any substantial share of the gender gap in housework, a considerable share of the gender gap still remains unexplained.

Consequently, because a greater share of gender differences in routine housework can still be attributed to gender discrimination and other unobserved variation, the results suggest but do not prove that there might be a persistent association of housework with 'women's work.' In other words, in Kyrgyzstan, just like in the US and Canada, women continue to do housework because social expectations require them to perform it, reflecting an inherently unjust and predefined process of housework division. These limitations might point in the direction of the gender-centered explanation of the division of housework (Bittman et al., 2003; Brines, 1994; Greenstein, 2000; Kolpashnikova, 2018).

One limitation of using Kyrgyz data is that time diary intervals are quite large (30 minutes). There is an overestimation in the duration of activities, particularly those, which do not require much time (cleaning and shopping). However, longer activities (such as paid work, cooking, and leisure) are likely to have been estimated more accurately. It could be valuable for future research to replicate these results using more accurate spousal diaries in other countries, for instance, Japan and France. 
Another limitation is the use of monetary measures of resources in countries like Kyrgyzstan. Personal income functions as an inadequate measure of resources in economically impoverished regions where wages are seldom paid in money but can be paid by other means. There is a clear need to develop additional ways to measure resources than income, absolute or relative alike.

The present results could be useful for policy-makers in showing how much of the gender equality at home can be achieved by leveling the opportunities of women in the labor market to those of men because the resource-based factors are still significant in accounting for the gender gap in time spent on routine housework. For most Kyrgyzstani women, equal work opportunities would alleviate their time spent on most housework tasks.

Additionally, housework scholarship could benefit from new theoretical frameworks accounting for structural factors within the gender-centered perspective, such as the processes of gendering and the systems of gender-based oppression. There is a value in developing quantifiable frameworks to measure gender bias because most of the gender gap can still be ascribed to factors outside of the resource-based explanations. 


\section{REFERENCES}

Álvarez, B., and Miles, D. (2003). Gender effect on housework allocation: Evidence from Spanish two-earner couples. Journal of Population Economics, 16(2), 227-242. DOI: https://doi.org/10.1007/s001480200126

Amarante, V., and Rossel, C. (2017). Unfolding Patterns of Unpaid Household Work in Latin America. Feminist Economics, 24(1), 1-34. DOI:

https://doi.org/10.1080/13545701.2017.1344776

Artis, J. E., and Pavalko, E. K. (2003, Aug). Explaining the Decline in Women's Household Labor: Individual Change and Cohort Differences. Journal of Marriage and Family, 65(3), 746-761. DOI: https://doi.org/10.1111/j.1741-3737.2003.00746.x

Baxter, J. (2002). Patterns of change and stability in the gender division of household labour in Australia, 1986-1997. Journal of Sociology, 38(4), 399-424. DOI: https://doi.org/10.1177/144078302128756750

Baxter, J., and Hewitt, B. (2013). Negotiating Domestic Labor: Women's Earnings and Housework Time in Australia. Feminist Economics, 19(1), 29-53. DOI:

https://doi.org/10.1080/13545701.2012.744138

Berk, S. F. (1985). The Gender Factory: The Apportionment of Work in American Households. New York, NY: Plenum. DOI: https://doi.org/10.1007/978-1-4613-2393-8 
Bianchi, S. M., Robinson, J. P., and Milkie, M. A. (2006). Changing Rhythms of American Family Life. New York, NY: Russell Sage Foundation. DOI: https://doi.org/10.1080/15267430902773337

Bittman, M., England, P., Sayer, L., Folbre, N., and Matheson, G. (2003). When Does Gender Trump Money? Bargaining and Time in Household Work. American Journal of Sociology, 109(1), 186-214. DOI: https://doi.org/10.1086/378036

Blair, S. L., and Lichter, D. T. (1991). Measuring the Division of Household Labor: Gender Segregation of Housework Among American Couples. Journal of Family Issues, 12(1), 91113. DOI: https://doi.org/10.1177/019251391012001007

Blinder, A. S. (1973). Wage Discrimination: Reduced Form and Structural Estimates. Journal of Human resources, 8(4), 436-455. DOI: https://doi.org/10.2307/144855

Blood, R. O., and Wolfe, D. M. (1960). Husbands and Wives, the Dynamics of Married Living. New York, NY: The Free Press.

Brines, J. (1994). Economic Dependency, Gender, and the Division of Labor at Home. American Journal of Sociology, 100(3), 652-688. DOI: https://doi.org/10.1086/230577

Brueck, T. (2015). Life in Kyrgyzstan Study. https://doi.org/10.15185/izadp.7055.1 
Coltrane, S. (1990). Birth Timing and the Division of Labor in Dual-Earner Families. Journal of Family Issues, 11(2), 157-181. DOI: https://doi.org/10.1177/019251390011002003

Coltrane, S. (2000). Research on Household Labor: Modeling and Measuring the Social Embeddedness of Routine Family Work. Journal of Marriage and Family, 62(4), 1208-1233. DOI: https://doi.org/10.1111/j.1741-3737.2000.01208.x

Craig, L., Powell, A., and Brown, J. E. (2016). Gender patterns in domestic labour among young adults in different living arrangements in Australia. Journal of Sociology, 52(4), 772788. DOI: https://doi.org/10.1177/1440783315593181

Davis, S. N., and Greenstein, T. N. (2009). Gender Ideology: Components, Predictors, and Consequences. Annual Review of Sociology, 35, 87-105. DOI: https://doi.org/10.1146/annurev-soc-070308-115920

Davis, S. N., and Greenstein, T. N. (2013). Why Study Housework? Cleaning as a Window Into Power in Couples. Journal of Family Theory \& Review, 5(2), 63-71. DOI: https://doi.org/10.1111/jftr.12004

Dernberger, B. N., and Pepin, J. R. (2020). Gender Flexibility, but Not Equality: Young Adults' Division of Labor Preferences. Sociological Science, 7, 36-56. DOI: https://doi.org/10.15195/v7.a2 
Deutsch, F. M. (2007). Undoing Gender. Gender and Society, 21(1), 106-127. DOI:

https://doi.org/10.1177/0891243206293577

Evertsson, M., and Nermo, M. (2004). Dependence within families and the division of labour: comparing Sweden and the United States. Journal of Marriage and the Family, 66(5), 1272-1286. DOI: https://doi.org/10.1111/j.0022-2445.2004.00092.x

Gershuny, J. (2000). Changing Times: Work and Leisure in Postindustrial Society. Oxford, UK: Oxford University Press.

Gimenez-Nadal, J. I., and Sevilla, A. (2012). Trends in time allocation: A cross-country analysis. European Economic Review, 56(6), 1338-1359. DOI:

https://doi.org/10.1016/j.euroecorev.2012.02.011

Goldberg, A. E. (2013). "Doing” and "Undoing” Gender: The Meaning and Division of Housework in Same-Sex Couples. Journal of Family Theory \& Review, 5(2), 85-104. DOI: https://doi.org/10.1111/jftr.12009

Greenstein, T. N. (2000). Economic dependence, gender, and the division of labor in the home: A replication and extension. Journal of Marriage and Family, 62(2), 322-335. DOI: https://doi.org/10.1111/j.1741-3737.2000.00322.x 
Guppy, N., and Luongo, N. (2015). The Rise and Stall of Canada's Gender-Equity Revolution. Canadian Review of Sociology, 52(3), 241-265. DOI:

https://doi.org/10.1111/cars. 12076

Guppy, N., Sakumoto, L., and Wilkes, R. (2019). Social Change and the Gendered Division of Household Labor in Canada. Canadian Review of Sociology/Revue canadienne de sociologie, 56(2), 178-203. DOI : https://doi.org/10.1111/cars.12242

Gupta, S. (2007). Autonomy, Dependence, or Display? The Relationship between Married Women's Earnings and Housework. Journal of Marriage and Family, 69(2), 399-417. DOI: https://doi.org/10.1111/j.1741-3737.2007.00373.x

Heer, D. M. (1963). The measurement and bases of family power: An overview. Marriage and Family Living, 25(2), 133-139. DOI: https://doi.org/10.2307/349170

Heitmueller, A. (2005). A note on decompositions in fixed effects models in the presence of time-invariant characteristics. IZA Discussion Paper No. 1886. Retrieved from: http://ftp.iza.org/dp1886.pdf

Hook, J. L. (2004). Reconsidering the Division of Household Labor: Incorporating Volunteer Work and Informal Support. Journal of Marriage and Family, 66(1), 101-117. DOI: https://doi.org/10.1111/1467-6478.00050-i1 
Hook, J. L. (2006). Care in Context: Men's Unpaid Work in 20 Countries, 1965-2003. American Sociological Review, 71(4), 639-660. DOI:

https://doi.org/10.1177/000312240607100406

Hook, J. L. (2010). Gender inequality in the welfare state: sex segregation in housework, 1965-2003. American Journal of Sociology, 115(5), 1480-1523. DOI: https://doi.org/10.1086/651384

Kan, M.-Y. (2008). Does gender trump money? Housework hours of husbands and wives in Britain. Work, Employment \& Society, 22(1), 45-66. DOI: https://doi.org/10.1177/0950017007087416

Kan, M.-Y., and He, G. (2018). Resource Bargaining and Gender Display in Housework and Care Work in Modern China. Chinese Sociological Review, 50(2), 188-230. DOI: https://doi.org/10.1080/21620555.2018.1430506

Kan, M.-Y., Hertog, E., and Kolpashnikova, K. (2019). Housework share and fertility preference in four East Asian countries in 2006 and 2012. Demographic Research, 41(35), 1021-1046. DOI: https://doi.org/10.4054/demres.2019.41.35

Kan, M.-Y., Sullivan, O., and Gershuny, J. (2011). Gender convergence in domestic work: Discerning the effects of interactional and institutional barriers from large-scale data. Sociology, 45(2), 234-251. DOI: https://doi.org/10.1177/0038038510394014 
Killewald, A., and Gough, M. (2010). Money isn't everything: Wives' earnings and housework time. Social Science Research, 39(6), 987-1003. DOI:

https://doi.org/10.1016/j.ssresearch.2010.08.005

Kolpashnikova, K. (2016). Housework in Canada: uneven convergence of the gender gap in domestic tasks, 1986-2010 University of British Columbia]. Vancouver, BC. DOI:

https://doi.org/10.14288/1.0340502

Kolpashnikova, K. (2018). American Househusbands: New Time Use Evidence of Gender Display, 2003-2016. Social Indicators Research, 140(3), 1259-1277. DOI:

https://doi.org/10.1007/s11205-017-1813-z

Kolpashnikova, K., and Kan, M.-Y. (2020). Hebdomadal Patterns of Compensatory Behaviour: Weekday and Weekend Housework Participation in Canada, 1986-2010. Work, Employment and Society (online first). DOI: https://doi.org/10.1177/0950017019868623

Moreno-Colom, S. (2016). The gendered division of housework time: Analysis of time use by type and daily frequency of household tasks. Time \& Society, 26(1), 3-27. DOI: https://doi.org/10.1177/0961463X15577269

Oaxaca, R. (1973). Male-Female Wage Differentials in Urban Labor Markets. International Economic Review, 14(3), 693-709. DOI: https://doi.org/10.2307/2525981 
Osmonaliev, A., Baijumanov, D., Kasymbekov, B., Tekeeva, L., Toktobekov, T., Orosbaev, A., Turdubaeva, C., and Biryukova, V. (2016). Surveys time budget. Bishkek, Kyrgyzstan: National Statistical Committee. Retrieved from:

http://new.stat.kg/en/publications/obsledovaniya-byudzheta-vremeni/

Pepin, J. R., Sayer, L. C., and Casper, L. M. (2018). Marital Status and Mothers' Time Use: Childcare, Housework, Leisure, and Sleep. Demography, 35(1), 107-133. DOI: https://doi.org/10.1007/s13524-018-0647-x

Presser, H. B. (1994). Employment Schedules Among Dual-Earner Spouses and the Division of Household Labor by Gender. American Sociological Review, 59(3), 348-364. DOI: https://doi.org/10.2307/2095938

Schieman, S., Ruppanner, L., and Milkie, M. A. (2018). Who helps with homework? Parenting inequality and relationship quality among employed mothers and fathers. Journal of Family and Economic Issues, 39(1), 49-65. DOI: https://doi.org/10.1007/s10834-017$9545-4$

Shelton, B. A. (1992). Women, men and time: Gender differences in paid work, housework and leisure. New York, NY: Greenwood Press. 
Sorensen, A., and McLanahan, S. (1987). Married Women's Economic Dependency, 19401980. American Journal of Sociology, 93(3), 659-687. DOI: https://doi.org/10.1086/228792

Steiner, S., and Becker, C. M. (2019). How marriages based on bride capture differ: Evidence from Kyrgyzstan. Demographic Research, 41, 579-592. DOI: https://doi.org/10.4054/DemRes.2019.41.20

Tai, T.-o., and Baxter, J. (2018). Perceptions of fairness and housework disagreement: A comparative analysis. Journal of Family Issues, 39(8), 2461-2485. DOI: https://doi.org/10.1177/0192513X18758346

Treas, J., and Tai, T. (2016). Gender Inequality in Housework Across 20 European Nations: Lessons from Gender Stratification Theories. Sex Roles, 74(11-12), 495-511. DOI: https://doi.org/10.1007/s11199-015-0575-9

Walker, J. (2013). Time poverty, gender and well-being: lessons from the Kyrgyz Swiss Swedish Health Programme. Development in Practice, 23(1), 57-68. DOI: https://doi.org/10.1080/09614524.2013.751357

West, C., and Zimmerman, D. H. (1987). Doing Gender. Gender \& Society, 1(2), 125-151. DOI: https://doi.org/10.1177/0891243287001002002 
Zhou, M. (2017). Motherhood, Employment, and the Dynamics of Women's Gender Attitudes. Gender \& Society, 31(6), 751-776. DOI: https://doi.org/10.1177/0891243217732320

Zhou, M., and Kan, M.-Y. (2019). A new family equilibrium? Changing dynamics between the gender division of labor and fertility in Great Britain, 1991-2017. Demographic Research, 40, 1455-1500. DOI: https://doi.org/10.4054/DemRes.2019.40.50 
[Appendix about here] 